\title{
Secular trends in sex ratios at birth in North America and Europe over the second half of the 20th century
}

\author{
V Grech, P Vassallo-Agius, C Savona-Ventura
}

J Epidemiol Community Health 2003;57:612-615

See end of article for authors' affiliations

.....................

Correspondence to: Dr V Grech, Paediatric Department, St Luke's

Hospital, Guardamangia, Malta;

victor.e.grech@govt.mt

Accepted for publication 2 January 2003

\begin{abstract}
Context: A previous study showed that significantly more boys were born in southern latitudes in Europe than in northern latitudes and the converse pattern was observed in North America.

Objective: This study analyses secular trends in gender ratios for live births over the second half of the 20th century.

Design, setting, participants: Analysis was carried out from a World Health Organisation dataset comprising live births over the above period. This included 127034732 North American and 157947117 European live births.

Main outcome measures: Analysis of trends in gender ratios for countries in both continents. Results: The findings show a highly significant overall decline in male births in both Europe and North America ( $p<0.0001)$, particularly in Mexico ( $p<0.0001)$. Interestingly, in Europe, male births declined in North European countries (latitude $>40^{\circ}, p<0.0001$ ) while rising in Mediterranean countries (latitude $\left.\cong 35-40^{\circ}, \mathrm{p}<0.0001\right)$. These trends produced an overall European male live birth deficit 238693 and a North American deficit of 954714 (total male live birth deficit 1193 407).

Conclusions: No reasonable explanation/s for the observed trends have been identified and the causes for these trends may well be multifactorial.
\end{abstract}

S ex in reptiles and fish is determined after conception, during embryogenesis, according to ambient environmental temperature. ${ }^{1}$ In contrast, in mammals and birds, sex is determined at conception. In mammals, male births invariably occur slightly in excess. ${ }^{2}$ The male to female ratio of live births is generally expressed as the ratio of male live births divided by total live births $(\mathrm{M} / \mathrm{F})$, and the human $\mathrm{M} / \mathrm{F}$ is expected to be 0.515 , with approximately $3 \%$ more males born than females. ${ }^{3}$ The reason for this discrepancy is uncertain as testicles produce equal numbers of X-bearing and Y-bearing spermatozoa. ${ }^{4}$

Several theories have been put forward to explain why this ratio should not be 0.5 , with equal number of male and female births. These theories include the timing of conception within the ovulatory cycle, ${ }^{3}$ endocrine effects, ${ }^{5}$ and immunological effects. $^{6}$

We have shown that $\mathrm{M} / \mathrm{F}$ varies in geographical space, exhibiting a latitude gradient, ${ }^{7}$ and that this gradient is different in Europe and North America, with more males born towards the south of Europe, compared with the North American continent where more males are born towards the north of the continent. ${ }^{8}$

Other studies have also shown that $\mathrm{M} / \mathrm{F}$ may vary with time. Several authors have shown that M/F has declined over the second half of the 20th century in various industrialised countries. These include Denmark, ${ }^{9}$ the United Kingdom, ${ }^{10}$ the Netherlands, ${ }^{11}$ Germany, ${ }^{12}$ Canada, ${ }^{13}$ the United States of America, ${ }^{14}$ and Finland. ${ }^{15}$ In contrast, $\mathrm{M} / \mathrm{F}$ has been noted to have risen in Ireland over the same period..$^{16} \mathrm{~A}$ non-significant rise in M/F has also been noted in Australia ${ }^{17}$ and Japan. ${ }^{18}$

James has proposed that M/F fluctuates over a 30 year cycle. ${ }^{19}$ In this study, we identify secular trends in $\mathrm{M} / \mathrm{F}$ in different countries and continents from a World Health Organisation dataset for the second half of the 20th century. We also analysed these trends by geographical latitude in Europe and briefly review the relevant literature regarding this topic.

\section{METHODS}

\section{Data sources}

Annual male and female live births were obtained directly from WHO. Data were available for 1950-97 for the North American continent (Canada, USA, and Mexico), and for European countries for the period 1950-99, with the following exceptions:

Data were not available for Mexico for the period 1950-8 and for 1996-7. Data were not available for the years 1998-9 for the following countries: France and Spain. Data were not available for 1999 for the following countries: the Netherlands, Poland, United Kingdom, Germany, Norway, and Greece. Data for Romania were not available for the period 1950-54. Stillbirths are not included in this study and neither were data from small countries.

\section{Statistics}

The quadratic equations of Fleiss were used for exact calculation of $95 \%$ confidence limits for ratios..$^{20}$ Linear regression was used for the calculation of association of annual M/F with time. Graphs are drawn as five year moving averages. A p value $\leqslant 0.05$ was taken to represent a statistically significant result.

\section{RESULTS}

There has been a significant decline in M/F ratios during the second part of the 20th century in both the European and North American continents (fig 1). Live birth data and regression calculations for countries studied are shown in table 1 .

\section{Europe}

This continent included a study (live birth) population of 157947 117. A statistically significant decrease in M/F was noted in Greece, Hungary, Poland, and Sweden. A decline in $\mathrm{M} / \mathrm{F}$, albeit not statistically significant, was found in Austria, Belgium, Bulgaria, Norway, Portugal, Romania, and Switzerland. In contrast, $\mathrm{M} / \mathrm{F}$ rose significantly in France and Italy. M/F rose and then fell in Spain, with an overall significant rise. 


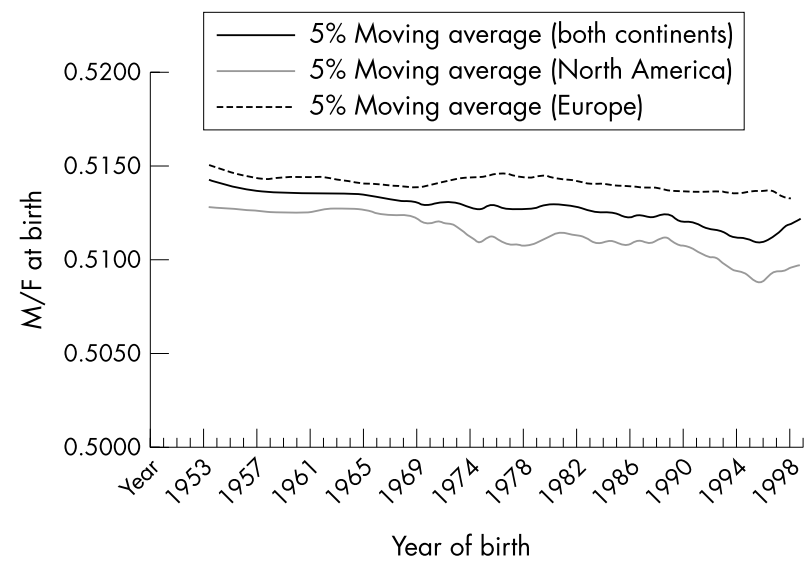

Figure $1 \mathrm{M} / \mathrm{F}$ ratios for Europe (combined), North America (combined), and both continents combined.

Summation of live births for Mediterranean countries that span latitude $\cong 35-40^{\circ}$ (Bulgaria, Greece, Italy, Portugal, and Spain) showed a significant rise in M/F. Live births for the remaining European countries above latitude $40^{\circ}$ (Austria, Belgium, Denmark, Finland, France, Germany, Hungary, Ireland, the Netherlands, Norway, Poland, Romania, Sweden, Switzerland, and the United Kingdom) showed a significant fall in $\mathrm{M} / \mathrm{F}$ (fig 2).

Assuming an expected $\mathrm{M} / \mathrm{F}$ of 0.515 , these trends produced a male birth deficit of 12744 in the Mediterranean region, 212780 in central Europe and 13169 in the Nordic countries; a total male birth deficit of births 238693 .

\section{North America}

This continent included a study (live birth) population of 127034 732. The combined North American continent data (Mexico, USA, and Canada) showed a significant decline in $\mathrm{M} / \mathrm{F}$ (fig $\mathrm{l}$ ). $\mathrm{M} / \mathrm{F}$ declined significantly in the USA and Mexico (fig 3).

Once again, assuming an expected $\mathrm{M} / \mathrm{F}$ of 0.515 , these trends produced a male birth deficit of 21993 in Canada,

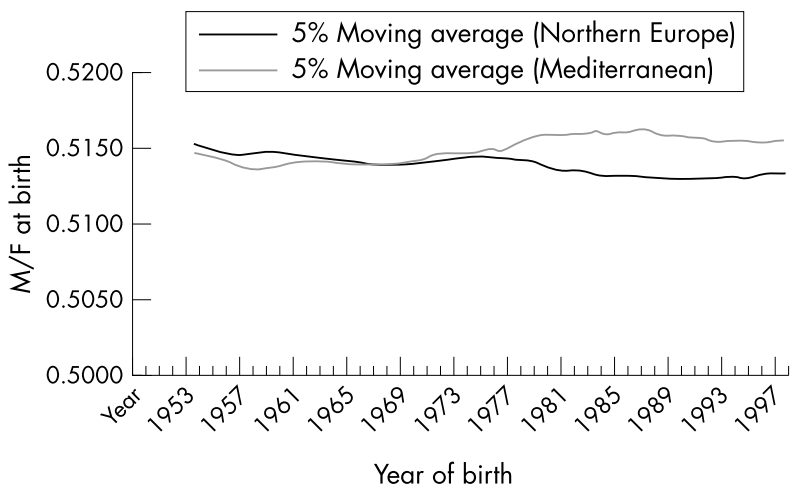

Figure 2 Summation of $M / F$ ratios for Mediterranean and northern European countries.

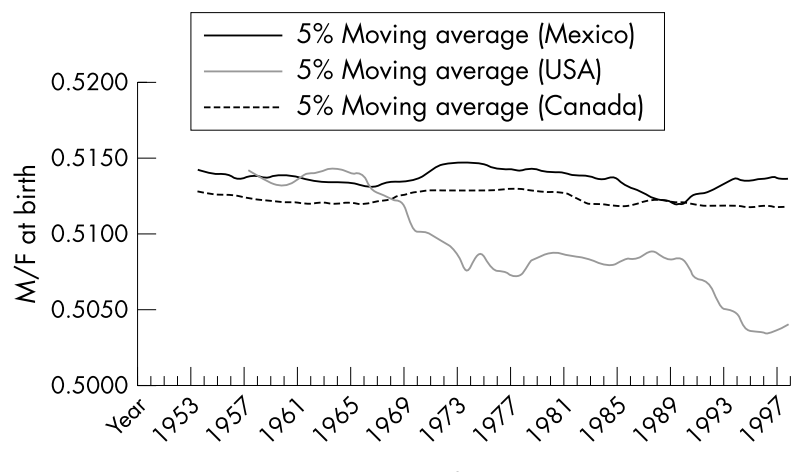

Year of birth

Figure $3 \mathrm{M} / \mathrm{F}$ ratios for Canada, the United States of America, and Mexico.

410932 in the United States, and 521789 in Mexico; a total male birth deficit of 954714 .

The combined live male birth deficit for the two continents was 1193407.

Table 1 Male, female, total births and linear regression of sex ratio with time for countries included in this study

\begin{tabular}{|c|c|c|c|c|c|c|c|}
\hline Country & Male live births & Female live births & Total live births & $r$ & $\mathrm{p}$ & $M / F$ & $95 \% \mathrm{Cl}$ \\
\hline Denmark* & 1680922 & 1588490 & 3269412 & -0.29 & 0.49 & 0.5141 & 0.5136 to 0.5147 \\
\hline Finland* & 1741682 & 1652473 & 3394155 & -0.10 & 0.50 & 0.5131 & 0.5126 to 0.5137 \\
\hline Germany* & 25678261 & 24239453 & 49917714 & -0.75 & $<0.0001$ & 0.5144 & 0.5143 to 0.5146 \\
\hline Ireland* & 1498481 & 1416062 & 2914543 & 0.45 & 0.002 & 0.5141 & 0.5136 to 0.5147 \\
\hline Netherlands* & 5160590 & 4899973 & 10060563 & -0.60 & $<0.0001$ & 0.5130 & 0.5126 to 0.5133 \\
\hline UK* & 20441737 & 19330020 & 39771757 & -0.61 & $<0.0001$ & 0.5140 & 0.5138 to 0.5141 \\
\hline Austria & 2600186 & 2466512 & 5066698 & -0.13 & 0.38 & 0.5132 & 0.5128 to 0.5136 \\
\hline Belgium & 3138073 & 2965932 & 6104005 & -0.17 & 0.26 & 0.5141 & 0.5137 to 0.5145 \\
\hline Bulgaria & 3176760 & 3000118 & 6176878 & -0.22 & 0.13 & 0.5143 & 0.5139 to 0.5147 \\
\hline France & 19579581 & 18634567 & 38214148 & 0.52 & $<0.0001$ & 0.5124 & 0.5122 to 0.5125 \\
\hline Greece & 3395944 & 3168572 & 6564516 & -0.43 & 0.002 & 0.5173 & 0.5169 to 0.5177 \\
\hline Hungary & 3815036 & 3587994 & 7403030 & -0.65 & $<0.0001$ & 0.5153 & 0.5150 to 0.5157 \\
\hline Italy & 18671513 & 17652250 & 36323763 & 0.73 & $<0.0001$ & 0.5140 & 0.5139 to 0.5142 \\
\hline Norway & 1444600 & 1363935 & 2808535 & -0.15 & 0.31 & 0.5144 & 0.5138 to 0.5149 \\
\hline Poland & 15295234 & 14359427 & 29654661 & 0.80 & $<0.0001$ & 0.5158 & 0.5156 to 0.5160 \\
\hline Portugal & 4283717 & 4015694 & 8299411 & -0.03 & 0.81 & 0.5161 & 0.5158 to 0.5165 \\
\hline Romania & 8082232 & 7649545 & 15731777 & -0.27 & 0.07 & 0.5138 & 0.5135 to 0.5140 \\
\hline Spain & 13600342 & 12805240 & 26405582 & 0.69 & $<0.0001$ & 0.5151 & 0.5149 to 0.5152 \\
\hline Sweden & 2607559 & 2459796 & 5067355 & -0.51 & $<0.0001$ & 0.5146 & 0.5141 to 0.5150 \\
\hline Switzerland & 2103563 & 1995775 & 4099338 & -0.07 & 0.65 & 0.5131 & 0.5127 to 0.5136 \\
\hline Mediterranean $\left(35-40^{\circ}\right)$ & 43128276 & 40641874 & 83770150 & 0.66 & $<0.0001$ & 0.5147 & 0.5148 to 0.5149 \\
\hline Northern Europe $\left(>40^{\circ}\right)$ & 114818841 & 108564205 & 223383046 & -0.84 & $<0.0001$ & 0.5139 & 0.5140 to 0.5141 \\
\hline All Europe & 157947117 & 149206079 & 307153196 & -0.68 & $<0.0001$ & 0.5142 & 0.5142 to 0.5143 \\
\hline Canada $\left(>50^{\circ}\right)^{*}$ & 8012882 & 7588817 & 15601699 & 0.26 & 0.79 & 0.5136 & 0.5133 to 0.5138 \\
\hline USA $\left(30-50^{\circ}\right)^{*}$ & 76827922 & 73150435 & 149978357 & -0.73 & $<0.0001$ & 0.5123 & 0.5122 to 0.5123 \\
\hline Mexico $\left(<30^{\circ}\right)$ & 42193928 & 40749212 & 82943140 & -0.76 & $<0.0001$ & 0.5087 & 0.5086 to 0.5088 \\
\hline North America & 127034732 & 121488464 & 248523196 & -0.73 & $<0.0001$ & 0.5112 & 0.5111 to 0.5112 \\
\hline
\end{tabular}




\section{DISCUSSION}

In utero, the male fetus is more prone to morbidity and mortality from external influences than the female fetus. Moreover, the male fetus is at greater risk of all obstetric complications than the female fetus and readers are referred to the review by Kraemer. ${ }^{21}$ Despite these adverse factors, males are invariably born in excess of females, ${ }^{2}$ implying an even higher conception rate of males over females than evinced by the sex ratio at birth.

In the first half of the 20th century, antenatal care improved dramatically in industrialised countries, which led to a fall in stillbirths, most of which would have otherwise been male. This therefore led to an increase in the M/F ratio.. ${ }^{92}$

$\mathrm{M} / \mathrm{F}$ then declined in several countries in the second half of the 20th century, and one study has proposed that M/F could be used as a sentinel health indicator. ${ }^{23}$ This is supported by data from Italy that showed that in metropolitan areas, M/F declined in comparison with the rest of the country where $\mathrm{M} / \mathrm{F}$ increased. ${ }^{24}$

However, there are several arguments against this hypothesis. Firstly, in Finland ${ }^{15}$ and in Malta, ${ }^{7}$ the decline in M/F predated the countries' industrialisation or the widespread use of pesticides. Secondly, it has been noted that in the United States, M/F was overall higher in the black population than in the white population, ${ }^{14}$ and that M/F rose and then fell in the white population (1964-1988), while rising throughout the study period in the non-white population. ${ }^{25}$ The overall decline is accounted for by the fact that over $80 \%$ of the USA population falls in the "white" category. Thirdly, Ireland has reported a rise in $\mathrm{M} / \mathrm{F}$ despite increasing industrialisation, ${ }^{16}$ and in this study, M/F was also seen to rise in France, Italy, and Spain. These findings do not support the sentinel health indicator hypothesis.

Our earlier study provoked several useful comments. ${ }^{8}$ Jacobs commented that the differences that we showed were very small, ${ }^{26}$ which is perfectly true. However, this small difference has resulted in an overall deficit of 1193407 male births in the European and North American continents for this same study period. ${ }^{8}$ Voracek and Fisher commented that as the onset of the study period in the 1950s is slightly different for Europe and North America, the peak in male live births after the second world war may have skewed our results. However, after the war, the ratio rapidly declined to the baseline and is therefore unlikely to have affected our overall results. ${ }^{11}{ }^{12}$ They also pointed out that that the area of the North American continent is 4.8 times the 24 European countries in our study. However, the data on which the paper is based show that the number of actual births is quite similar (North America 127034 732, Europe 157947 117, ratio 0.80). They also reanalysed the dataset and showed a curvilinear relation of latitude and sex ratio that is consistent with an effect related to photoperiod. However, the secular trends cannot be explained, to our mind, by such an effect. ${ }^{27}$ Shields et al showed a significant relation between cytomegalovirus seropositivity in cord blood and female sex, but again, we cannot see how CMV infection may possibly be implicated in these secular trends. ${ }^{28}$

James also reiterated the influence of maternal oestrogen levels on birth weight and the likelihood of dizygotic twins. ${ }^{29}$ While an interesting hypothesis, we cannot see how this factor alone could explain the widely varying secular trends in different countries over the same timespans.

An earlier study had noted declining trends in several countries in various continents, but a latitude effect had not been perceived. ${ }^{30}$ This same study also showed no overall change in M/F over 1926-1990, whereas our study only looked at the second half of 20th century. It may be that Parazzini et al's early part of the dataset trends nullified the trends in the second half of 20 th century. ${ }^{31}$

External factors that influence $\mathrm{M} / \mathrm{F}$ have also been described. Germany, for example, experienced two M/F peaks that were related to the two world wars, ${ }^{12}$ and these peaks were also supported by data from the Netherlands. ${ }^{32}$

James has proposed that M/F fluctuates over a 30 cycle, and that this is attributable to a homeostatic mechanism that correlates sex at birth negatively with the adult sex ratio at the time of conception. ${ }^{33}$ The current decline in M/F would therefore be a negative feedback response to the increase in M/F in the first half of the 20th century. This hypothesis is partly supported by data from the USA that demonstrated a degree of cyclicity over a 55 year period..$^{30}$ More interestingly, this same study showed a strong degree of correlation between parental age and birth weight. However, the overall decline in $\mathrm{M} / \mathrm{F}$ in our 50 year study seems constant in both Europe and North America (fig 1) with no evidence of a 30 year cycle.

Diverging cultural attitudes may also potentially influence M/F. For example, Latino and Eastern cultures prefer male over female offspring. ${ }^{34}{ }^{35}$ In such cultures, families would be more likely to settle for a single son, than for a single daughter, and on first having a daughter, may therefore opt to have additional children in order to have a son. Male offspring bias may also be evinced by female infanticide and/or sex selective abortion. However, it is unlikely that such factors could have played an important part in determining the observed $\mathrm{M} / \mathrm{F}$ ratios in the developed countries considered in this study. ${ }^{36}{ }^{37}$ Moreover, any such skew would have mitigated against our finding of an overall male deficit.

Several other hypothesis have been put forward to explain different trends in $\mathrm{M} / \mathrm{F}$ ratios, with various factors assumed to influence the female genital tract environment in ways to favour the Y-bearing spermatozoa. ${ }^{25}$ For example, it has been claimed that caloric availability per capita correlates positively with $\mathrm{M} / \mathrm{F}^{37}$

In an earlier study we showed a latitude gradient for both Europe and the North American continent. ${ }^{8}$ Our current European results are interesting in that they show a rising $\mathrm{M} / \mathrm{F}$ ratio in Mediterranean countries and a falling $\mathrm{M} / \mathrm{F}$ ratio in more northern European countries (fig 2). Since the early 1980s, in Mediterranean countries, M/F ratio seems to have stabilised at just over the expected value of 0.515 , while in more northern countries, M/F ratio seems to have stabilised at 0.513. Should these secular trends increase in magnitude, with an increasing male deficit, this will naturally have social, occupational, epidemiological, and community health related effects. The results of this study yield highly significant $p$ values because of the large numbers of births involved despite the comparatively small shifts in secular trends. The $p$ values are usually used to enable inferences to be drawn about populations from samples. In this context, the $p$ value is only useful as an indicator that shows how likely it is that these results should occur by chance alone, assuming that the dataset is correct. One final point that must be borne in mind is that the differences that we demonstrated are very small, and could theoretically have been produced by even very small differential reporting in male and female births, although such errors are unlikely to produce the observed, rather smooth secular trends.

In conclusion, while we have expanded our findings on the sex ratio at birth by studying secular trends, we still cannot put forward any reasonable explanation for the observed trends, which may well be attributable to several factors and not just one.

Authors' affiliations

V Grech, Paediatric Department, St Luke's Hospital, Malta

P Vassallo-Agius, Medical School, University of Malta

C Savona-Ventura, Department of Obstetrics and Gynaecology, St

Luke's Hospital, Malta

\section{REFERENCES}

1 Dournon C, Houillon C, Pieau C. Temperature sex-reversal in amphibians and reptiles. Int J Dev Biol 1990;34:81-92. 
2 Parkes AS. The mammalian sex ratio. Hum Reprod 1926:2:1-51.

3 James WH. The human sex ratio. Part 1: a review of the literature. Hum Biol 1987;59:721-52.

4 Wyrobek AJ, Robbins WA, Mehraein Y, et al. Detection of sex chromosomal aneuploidies $X-X, Y-Y$, and $X-Y$ in human sperm using two-chromosome fluorescence in situ hybridization. Am J Med Genet 1994:53:1-7.

5 James WH. Parental hormone levels and mammalian sex ratios at birth J Theor Biol 1989;139:59-67.

6 Ober C. The maternal-fetal relationship in human pregnancy: an immunogenetic perspective. Exp Clin Immunogenet 1992;9:1-14.

7 Grech V, Vassallo-Agius P, Savona-Ventura C. Declining male births with increasing geographical latitude in Europe. J Epidemiol Community Health 2000;54:244-6.

8 Grech V, Vassallo-Agius P, Savona-Ventura C. BM 2002;324:1010 11.

9 Moller H. Change in male:female ratio among newborn infants in Denmark. Lancet 1996;348:828-9.

10 Dickinson HO, Parker L. Why is the sex ratio falling in England and Wales? J Epidemiol Community Health 1996:50:227-8.

11 van der Pal-de Bruin KM, Verloove-Vanhorick SP, Roeleveld N. Change in male:female ratio among newborn babies in Netherlands. Lancet 1997;349:62

12 Bromen $\mathbf{K}$, Jockel $\mathrm{KH}$. Change in male proportion among newborn infants. Lancet 1997;349:804-5.

13 Allan BB, Brant R, Seidel JE, et al. Declining sex ratios in Canada. Can Med Assoc J 1997;156:37-41.

14 Marcus M, Kiely J, Xu F, et al. Changing sex ratio in the United States, 1969-1995. Fertil Steril 1998:70:270-3.

15 Vartiainen T, Kartovaara L, Tuomisto J. Environmental chemicals and changes in sex ratio: analysis over 250 years in Finland. Environ Health Perspect 1999;107:813-15

16 Moynihan JB, Breathnach CS. Changes in male:female ratio among newborn infants in Ireland. APMIS 1999;107:365-8.

17 Lancaster PA, Day PL. Declines in population sex ratios at birth. JAMA 1998;280:1 139-40.

18 Minakami $\mathbf{H}$, Sato I. Change in male proportion of newborn infants in Japan. Am J Obstet Gynecol 1998;178:624.

19 James WH. Declines in population sex ratios at birth. JAMA 1998;280: 1139.
20 Fleiss JL. Statistical methods for rates and proportions. 2nd edn. New York: Wiley, 1981:14-15.

21 Kraemer S. The fragile male. BM 2000;321:1609-12.

22 National Center for Health Statistics. Vital statistics of the United States, 1992: mortality part A. Vol 2. Washington, DC: Public Health Service, 1996.

23 Davis DL, Gottlieb MB, Stampnitzky JR. Reduced ratio of male to female births in several industrial countries: a sentinel health indicator? JAMA 1998;279: 1018-23.

24 Astolfi P, Zonta LA. Reduced male births in major Italian cities. Hum Reprod 1999;14:3116-19.

25 Nicolich MJ, Huebner WW, Schnatter AR. Influence of parental and biological factors on the male birth fraction in the United States: an analysis of birth certificate data from 1964 through 1988. Fertil Steril 2000;73:487-92

26 Jacobs A. Different sex ratios at birth in Europe and North America. [Letter]. BM 2002;325:334.

27 Voracek M, Fisher ML. Different sex ratios at birth in Europe and North America. [Letter]. BM 2002;325:334.

28 Shields MD, O'Hare B, Nelson J, et al. Different sex ratios at birth in Europe and North America. [Letter]. BM 2002;325:334.

29 James WH. Sex ratio at birth and latitude. [Letter]. J Epidemiol Community Health $2001 ; 55: 216$

30 Parazzini F, La Vecchia C, Levi F, et al. Trends in male:female ratio among newborn infants in 29 countries from five continents. Hum Reprod 1998;13:1394-6.

31 Parazzini F, La Vecchia C, Chatenoud L, et al. Change in male proportion among newborn infants. Lancet 1997;349:805-6.

32 van den Broek JM. Change in male proportion among newborn infants. Lancet 1997;349:805

33 James WH. What stabilizes the sex ratio? Ann Hum Genet 1995;59:243-9.

34 Sachar RK, Soni RK. The role of secondary sex ratios in the declining sex ratio of India. Indian J Public Health 1995;39:12-15.

35 Coale AJ, Banister J. Five decades of missing females in China. Demography 1994;31:459-79.

36 Rinehart W. Sex preselection-not yet practical. Popul Rep 1975;2:21-32.

37 Williams RJ, Gloster SP. Human sex ratio as it relates to caloric availability. Soc Biol 1992;39:285-91.

\section{APHORISM OF THE MONTH}

\section{Starting a rumour, following Christopher Columbus, and spending other people's money}

$\mathrm{R}$ eaders will recall that Columbus was adept at following his strategy for exploration by spending other people's money. ${ }^{1}$ Bridging the gap between starting a rumour and mobilising resources for change is at the heart of public health-how often have you heard somebody say that they can't do anything to improve health without knowing where the money is coming from first, yet public health is essentially about shaping and influencing the actions of others and other sectors. An effective public health practitioner should be adept at spending other people's money, but for this to happen on any meaningful scale it is essential for other players involved to feel a sense of ownership. ${ }^{2}$ I have long contended that in health and health care we need not Directors of Finance, but Directors of Resources. The mindset that starts with financial resources in health finishes up with doctors, nurses, bricks and mortar, and bits of kit. In reality, the resources for health run much wider, including many human and environmental resources that lie outside the bailiwick of something called health.

\section{References}

JRA

1 Ashton JR. Columbus on the need for strategy. J Epidemiol Community Health 2003;57:235

2 Ashton JR. Communities and sustaining change. J Epidemiol Community Health 2002;56:561. 